\title{
Study of the effect of nanocomposites based on humic substances of different nature on the causative agent of ring rot of Clavibacter michiganensis ssp. sepedonicus potato plants
}

\author{
O.A. Nozhkina ${ }^{1 *}$, A.I. Perfilyeva ${ }^{1}$, I.A. Graskova ${ }^{1}$, B.G. Sukhov ${ }^{2}$ \\ ${ }^{1}$ Siberian Institute of Physiology and Biochemistry of Plants SB RAS, Irkutsk, Russia \\ ${ }^{2}$ Irkutsk Institute of Chemistry of A.E. Favorskii SB RAS, Irkutsk, Russia \\ *e-mail: alla.light@mail.ru,smallolga@mail.ru
}

Key words: silver nanocomposites, ring decay, humic substances, activity level peroxydase

Motivation and Task: Plants of potatoes transfer the dangerous bakterilny disease caused Clavibacter michiganensis ssp. sepedonicus. Bacteria complicate food of plants, causing withering and death, thereby bring to a yield loss. There are no ecologically safe measures for fight against this disease, all measures come down only to disinfecting. Therefore, there was a need for search of safe and effective remedies with a disease. Argentiferous nanocomposites (NC) based on natural components of various humic substances (HS) can be such substances. They not toxicity, are steady for a long time, are factors of growth of plants and a soil-forming biota, etc.

Methods and Algorithms: Were investigated AC 1405 strain bacteria, three types of the $\mathrm{NC}$ silver packed into HS and their predecessors by HS (NCHS - dirt/AgNO $3, \mathrm{NCNS}_{-}$ coals $/ \mathrm{AgNO}_{3}, \mathrm{NCNS}$ - slates $/ \mathrm{AgNO}_{3}$, HS - dirt, $\mathrm{HS}$ - coals, $\mathrm{HS}$ - slates and nitrate of silver) and plants of potatoes of a grade of Lukyanovsky. All substances were synthesized at the Irkutsk institute of chemistry by it A.E. Favorskii, soluble in water is good and the water decisions are convenient in use. Bacteria grew up 2-3 days, after incubated the $\mathrm{NC}$ and its predecessors. Studying of bactericidal effect of the $\mathrm{NC}$ and formation of the biomovie is executed by measurement of optical density of bacterial suspension. plants grew up on nutrient medium of Murasige-Skuga in faktorostatnykh conditions within 14 days. Further NC and HS incubated. Each 2 days took measurements of biometric parameters of plants and activity of peroxidase.

Results and Discussion: The bakteriostatic effect was shown by the predecessor of $\mathrm{NC}-\mathrm{AgNO}_{3}$ considerably suppressed growth of bacteria from the beginning of the experiment. So, HS-cl and HS-sl and their NC inhibited growth of bacteria and ability of a biofilm formation. HS-dt and its NC stimulated reproduction of bacteria, and reduced formation of biofilms. HS-cl stimulated reproduction of a bacterium. After processing of plants of the $\mathrm{NC}$ and their predecessors, was analyzed peroxidase in potatoes plants. that was revealed $\mathrm{AgNO}_{3}$, HS-dt, HS-sl, NCHS-dt/AgNO 3 , NCHS-sl/AgNO 3 more than twice reduced activity of peroxidase. $\mathrm{HS}-\mathrm{cl}$ and $\mathrm{NCHS}-\mathrm{cl} / \mathrm{AgNO}_{3}$ stimulated activity of peroxidase of potatoes and on biofilm formation of bacteria.

Conclusion: Studying influence of antibacterial activity of $\mathrm{NC}$ on $\mathrm{Cms}$, showed us that use of NC based on HS as safe means of fight against a bacterial disease of plants of potatoes is possible.

Acknowledgements: Work is performed with financial support of the Russian Federal Property Fund and Government of the Irkutsk region (project No. 17-416-380001 of a r_). 